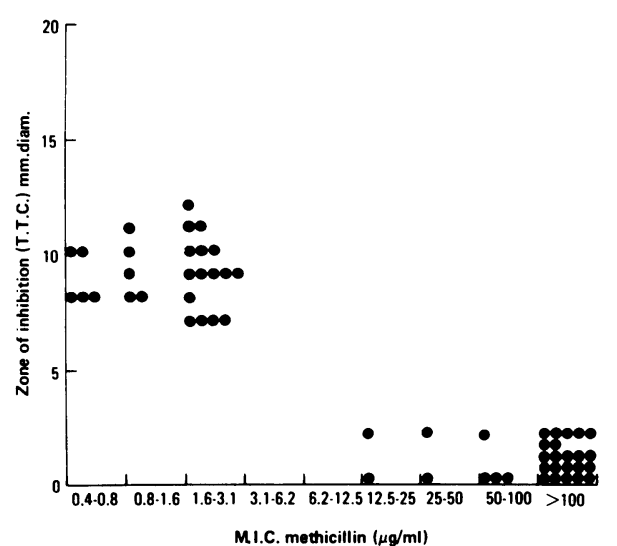

FIG. 2-Correlation of zone size (less diameter of disc) with M.I.C. methicillin determined after 18 hours incubation at $30^{\circ} \mathrm{C}$.

are usually regarded as sensitive. The rapid sensitivity test reliably distinguishes between these and methicillin-resistant staphylococci. -We are, etc.,

J. G. KENSIT

Guy's Hospital,
London S.E.1

N. A. SIMMONS

1 Knox, R., British Medical fournal, 1961, 1, 126.

. British Medical Fournal, 1961, 1,125 .

Churcher, G. M., Journal of Clinical Pathology,

1968, 21, 213., Medical fournal of Australia, 1968, 1, 444. Coe, A. W., and Parker, M. T.

fournal of Medical Microbiology, 1969, 2, 443.

\section{Chlorprothixene and Obstructive Jaundice}

SIR,-Cholestatic jaundice, which can complicate treatment with phenothiazines and to a lesser extent with butyrophenones, is reported to occur only rarely with chlorprothixene. ${ }^{1}$ We therefore report the following case of severe obstructive jaundice occurring during treatment with this drug.

A 59-year-old man was admitted to hospital on 15 June 1972 with acute mania. His past history included mild diabetes mellitus, acute myocardial infarction in 1967, and a cerebrovascular accident in 1970 from which he had fully recovered. During a previous inaniac phase in 1971 he had been treated briefly with chlorprothixene (Tarasan) with no ill effects. On admission he was started on Tarasan $100 \mathrm{mg}$ daily intramuscularly and $50 \mathrm{mg}$ orally four times a day as well as digoxin, aldactazide, and chlorpropamide for his various medical conditions. Over the next three to four days he became more co-operative and amiable. On 23 June his skin was slightly yellow, but was thought to be its normal hue. On 27 June Tarasan injections were discontinued and the oral dose increased to $50 \mathrm{mg}$ four times a day. Next day the patient developed a spiking fever and was deeply jaundiced. His liver function tests, previously normal, became quite abnormal. Blood cultures showed a pneumococcal septicemia and a chest $x$-ray confirmed bronchopneumonia. All medication was stopped. Antibiotics brought his infection under control, but he remained deeply jaundiced. On 7 July his bilirubin dropped dramatically and he was eventually discharged with normal liver function. Subsequent investigations showed no evidence of gallstones and the uninterrupted recovery from the jaundice eliminated the possibility of carcinoma, leaving Tarasan as the most likely cause of the jaundice, though chlorpropamide could not be excluded.

Stefko and $\mathrm{Zbinden}^{2}$ measured bile flow and interbiliary pressure in anaesthetized, cholecystectomized dogs during administra- tion of several different drugs. Whereas chlorpromazine within the range of therapeutic dosage produced a decrease in bile flow and a marked increase in intraductal pressure, chlorprothixene had no effect on these functions. On the other hand, Tesarovâ et al. ${ }^{3}$ showed that while chlorprothixene had no apparent hepatotoxic effects in most cases it might cause slight changes in liver function within normal limits in up to $29 \%$ of cases and even give pathological results in some. These were reversible in all cases.

How neuroleptic and other drugs produce cholestatic jaundice is uncertain. Increased bile viscosity, ${ }^{4}$ disordered mobility of the ducts, ${ }^{5}$ and damage to the walls of the ductules causing leakage, inspissation, and regurgitation of bile ${ }^{6}$ have all been held responsible, though there the direct effect on the ductules may be contributary rather than the sole cause of the jaundice. ${ }^{2}$ All three would result in slowing of bile flow or increase in pressure, and it has been suggested that these should be assessed routinely during the screening of new drugs. ${ }^{2}$ Nevertheless, the present case would suggest that these tests even when negative, as indeed they were for chlorprothixene, do not totally eliminate the danger of cholestatic jaundice. -We are, etc.,

\section{G. S. RUDDOCK} J. HOENIG

Memorial University of Newfoundland,

St. John's, 1 Ban, T., Psychopharmacology, Baltimore, Williams

Stefko, P. L., and Zbinden, G., Fournal of Gastroenterology, 1963, 39, 410 .

3 Tesarová, O., Molcan, J., and Jenca, G., Activitas Nervosa Superior, $1963,5,204$.

Werner, S. C., Hanger, F. M. and Kritzler, K. A., American Fournal of Medicine, 1950, 8, 325 .

Besson, F., Schweizerische medizinische Wochenschrift, 1956, 86, 1020

Reichel, J., Goldberg, S. B., Ellenberg, M., and $1960,28,654$.

\section{Hodgkin's Disease: a Clue or a Fluke?}

SIR,-It was with considerable interest that I read the leading article on Hodkin's disease (9 December, p. 564). There is a histological subtype (often called Hodgkin's) which occurs in dogs and cats. We own bullmastiffs, and in this breed the incidence of this type of "leukaemia" is, to quote one veterinary surgeon, ludicrously high. It is virtually unknown in some other breeds. There is a marked family connexion in many cases and there are at least three well-known sires (unaffected themselves) whose second and third generation progeny show a high incidence "showing clustering." In our own case we lost a dog about three years ago with this condition. We now have another which exhibits lymphosarcoma. The granddam of this dog was full litter sister to our last dog. $\mathrm{He}$ also has a sire whose grandsire was full litter brother to another dog which died from this condition.

It is easy to check the family relationship in these animals, as pedigrees are always obtainable. This is a numerically small breed, and at the present the breed is losing an average of six animals a year from this disease with a sex ratio of rather more than two males to one female. There would seem to be two distinct "incubation periods"young (at about $2-2 \frac{1}{2}$ years) and mature (at about $6-7 \frac{1}{2}$ years). It will be appreciated that until an animal has reached 8 years it cannot be considered "free," and that some dogs will die from other causes before they are old enough to develop the condition. This creates statistical problems. There is no clinical evidence to show which puppy will develop the disease. We know one instance of two animals from the same litter which succumbed to the disease within a few months of each other but in different countries (one had been exported), and therefore environment was excluded.

Many breeders can remember dogs dying from this disease many years ago and the family relationship can be traced through pedigree for several generations. It is also interesting that fellow breeders in the U.S.A. have this condition in their stock. These animals are from the same bloodlines and ancestors as those in Britain-again in a different environment.

A virus was found in cats. It is passed by direct transmission, but the method of infection is as yet unknown. ${ }^{1}$ I suspect that when further evidence has been collated we may find this to be so in the bullmastiff. A similar "leukaemic" condition is known in poultry and mice. I hope that scientific research into serious medical problems in our companion animals will improve their health and help further understanding in man.-T am, etc.,

\section{Worcester}

JEAN ClaRk

1 Animal Health, 1969, No. 11, p. 14.

\section{Thiocyanate Metabolism in Human Vitamin $\mathbf{B}_{12}$ Deficiency}

SIR,-Dr. D. G. Wells and others (9 December, p. 588) have focused attention on the role of chronic cyanide intoxication in the aetiology of subacute combined degeneration of the cord. The association between smoking and subacute combined degeneration is confirmed in this study but remains unexplained and, as stated by the authors, their results "provide no support for the hypothesis that chronic cyanide intoxication is responsible for the occurrence of neurological disease in a minority of patients with vitamin $\mathrm{B}_{12}$ deficiency, although they do not conclusively exclude this possibility."

I would like to comment on the differing sex incidence in the authors' patients with uncomplicated pernicious anaemia and subacute combined degeneration and in patients with retrobulbar neuritis whom $\mathrm{Dr}$. J. M. Heaton and I reviewed in 1961..$^{1}$ Although there were more men (and more smokers) among their patients with subacute combined degeneration than in those presenting with anaemia, the overall preponderance of females in patients with subacute combined degeneration noted in this and in earlier studies $^{2}$ is in marked contrast to our findings in retrobulbar neuritis. Our original thesis that retrobulbar neuritis in pernicious anaemia could not be satisfactorily explained on the basis of vitamin $B_{12}$ deficiency alone was based on a critical analysis of 31 cases. Firstly, we noted that there was an overwhelming male preponderance, in that 28 were men. Secondly, it was evident that the development of retrobulbar neuritis in patients with pernicious anaemia was not related to the duration of the disease, to the presence or degree of anaemia, or to diffuse neurological involvement. Unfortunately, we found a lack of precise information about the smoking habits in 31 case reports of 